\title{
IMMEDIATE EFFECT OF KINESIO TAPE ON GAIT SYMMETRY IN PATIENTS WITH STROKE: A PRELIMINARY STUDY
}

original paper

(1) University School of Physical Education in Wroclaw

DOI: https://doi.org/10.5114/hm.2020.88156

\section{ANECHA HORASART, WANALEE KLOMJAI, SUNEE BOVONSUNTHONCHAI}

Faculty of Physical Therapy, Mahidol University, Nakhon Pathom, Thailand

\begin{abstract}
Purpose. Asymmetrical gait pattern usually occurs in patients with stroke. It contributes to excessive energy expenditure during movement and leads to injury and risk of fall. More symmetry, therefore, is set as a goal of gait restoration. The aim of the study was to explore the immediate effect of Kinesio Tape (KT) on gait symmetry and to investigate the correlation of motor function and gait symmetry.

Methods. Ten patients with stroke and foot drop were objectively examined for temporo-spatial and kinematic variables with a 3D motion analysis system. Assessments were performed before and immediately after taping. KT was applied with the inhibition technique for the ankle plantar flexor muscle and with the functional correction technique for the ankle dorsiflexion and eversion. Symmetry indices (SI) of the temporo-spatial and kinematic variables were calculated to present gait symmetry between the affected and unaffected sides. Correlations between motor function established with the Fugl-Meyer assessment for lower extremity (FMA-LE) with SI of the temporo-spatial and kinematic variables before and after taping were investigated.
\end{abstract}

Results. Improvements of step length and step time symmetry were found after taping. In addition, more symmetry of the single support time, hip extension, knee flexion, and ankle plantar flexion angles was observed, but the difference was not significant. A significant correlation of FMA-LE was reported with SI of step length but not of the other variables.

Conclusions. KT positively affected gait symmetry in patients with stroke suffering from foot drop.

Key words: stroke, athletic tape, gait, foot drop

\section{Introduction}

Stroke is a cerebrovascular disease caused by ischemic or haemorrhagic conditions. It leads to loss of bodily function that is controlled by the brain [1]. An epidemiology study of stroke in Thailand of 2014 showed a prevalence of $1.88 \%$ among adults aged 45 years or more, and the mean age of onset was 65 years [2]. It is one of the major health burdens worldwide and often results in daily living activities dependency [3].

Several changes are usually present in patients with stroke, involving alterations of muscle tone, muscle length, sensation, and balance [4]. Abnormal gait pattern is among the most common issues after stroke [5]. More than $70 \%$ of patients with stroke have problems at the ankle joint that lead to excessive ankle plantar flexion, lack of ankle dorsiflexion, or foot stuck in the supination position [6]. Most patients with stroke present gait deviations with altered temporo-spatial and kinematic variables. Temporo-spatial deviations are characterized by a decrease in the affected step length, stride length, single support time, gait speed, cadence, and short step time of the unaffected leg, while the double support time is increased [7]. Kinematic deviations are associated with a reduction of the affected hip, knee, ankle angles amplitude in the sagittal plane. It is generally accepted that the speed and distance of walking are important for the clinical endpoints in pathologic conditions [8, 9]. However, the different changes that occur on the affected and unaffected sides produce an asymmetrical gait pattern in patients with stroke. This asymmetry results in walking difficulty, increase in energy expenditure, and risk of falls $[10,11]$.

Correspondence address: Sunee Bovonsunthonchai, Faculty of Physical Therapy, Mahidol University, 999 Phuttamonthon 4 Rd., Salaya, Phuttamonthon, Nakhon Pathom, 73170, Thailand, e-mail: sunee.bov@mahidol.edu

Received: March 16, 2019

Accepted for publication: August 23, 2019

Citation: Horasart A, Klomjai W, Bovonsunthonchai S. Immediate effect of Kinesio Tape on gait symmetry in patients with stroke: a preliminary study. Hum Mov. 2020;21(1):73-81; doi: https://doi.org/10.5114/hm.2020.88156. 
A. Horasart, W. Klomjai, S. Bovonsunthonchai, Effect of Kinesio Tape on gait symmetry in stroke

Various therapeutic interventions such as assistive devices, electromechanical-assisted or physical therapy techniques have been created to improve gait performance in patients with stroke $[8,12-14]$. The major functions of Kinesio Tape (KT) based on Kase theory include pain reduction, removing congestion of lymphatic fluid or blood under the skin, weak muscles support, and joint malalignment correction [15]. KT advantages over the rigid tape are unrestricted joint range of motion and the possibility to attach for several days on the skin. It can be applied as an alternative intervention method for neurological conditions such as stroke, spinal cord injury, and Parkinson's disease [16]. KT techniques may be used to either inhibit or facilitate muscles and also to stimulate proprioceptive sense and increase sensory feedback via pressure or stretch [17]. With several methods of application, KT can serve to improve gait performance through facilitating the walking technique [18]. In 2012, Kim et al. studied the effect of KT on static and dynamic balances and gait velocity in patients with stroke [19]. They applied KT accompanied by therapeutic exercise to facilitate tibialis anterior, inhibit gastrocnemius muscles, and stabilize the ankle joint. The results showed a significant improvement in balance and gait. A study performed by Kim et al. in 2014 [20] investigated change in gait velocity, straight line walking test, and balance when KT was applied to facilitate upper and lower extremities of the affected side in patients with stroke. A positive effect of KT on the improvement of typical asymmetrical gait was reported. However, the authors suggested that a valid tool should be used to evaluate gait symmetry more explicitly.

Motor function is an important factor contributing to the quality of movement. It was usually described with multi-dimensional perspectives following the International Classification of Functioning. One of the popular assessment tools is the Fugl-Meyer assessment scale, constructed by Fugl-Meyer et al. in 1975 [21]. It is a standardized test for post-stroke recovery based on the sensorimotor function. The test is divided into parts referring to upper and lower extremity functions, with the full scores of 66 and 34, respectively. The relationship between the lower extremity function and gait parameters in patients with stroke has been determined in previous studies [22, 23]. The findings showed different results among the studies owing to different factors such as population, data collection process, outcome measures, and the tools applied. Among various gait parameters, gait speed is usually found to report gait performance and used as a treatment goal $[8,24,25]$. However, there may be limitations involving the quality of movement or compensatory movement, often expressed as gait asymmetry in patients with stroke. It can be observed that previous studies investigated gait symmetry and tried to find a method to measure it for clinical application [10, 26-28].

As mentioned above, the application of KT has demonstrated a beneficial impact on gait speed, step length, step time, and balance in patients with stroke. However, information about gait symmetry after KT use is limited. Because gait symmetry is used as an indicator of performance and relates to the risk of fall in the population being described, the purpose of this study was, firstly, to investigate the immediate effect of KT on gait symmetry in patients with stroke and, secondly, to examine the correlation of motor function and gait symmetry before and after taping. We hypothesized that more symmetrical gait can be obtained after KT application. In addition, we expected to observe a correlation between motor function and gait symmetry in patients with stroke.

\section{Material and methods}

\section{Study design}

We performed a study with a single group, pretestposttest design.

\section{Participants}

Ten patients with stroke were recruited from the Physical Therapy Center, Faculty of Physical Therapy, Mahidol University. The inclusion criteria were age of 20-80 years; first stroke with onset between 1 month to 2 years; present observable gait problems such as insufficient ankle dorsiflexion, toe drag, abnormal foot supination during the swing or stance phases of gait; mild spasticity of the ankle plantar flexors and invertors assessed by the Modified Ashworth Scale (MAS; score $\leq 2)$; ability to walk at least 10 meters with or without using a cane; understanding of instructions and ability to follow the research protocols; no cognitive impairment as evaluated by the Thai Mental State Examination (TMSE; score > 23); normal or partial impairment of proprioceptive sensation at the ankle joint; and exteroceptive sense in the foot and leg areas. Participants were excluded if they had visual deficits, ankle joint contracture, opened wound at the shank, calf, or foot, or presented other neurological conditions. 
Screening for the above-mentioned criteria, recording of sex, affected side, age, and onset, as well as physical examination including the Fugl-Meyer assessment for lower extremity (FMA-LE) and MAS for the hip adductor, hip extensor, knee extensor, ankle plantar flexor, and ankle invertor muscles were performed before data collection.

\section{Data collection protocol}

Walking data were collected twice, before and immediately after KT application, with the use of 10 cameras of the Vicon ${ }^{\mathrm{TM}}$ Motion Analysis System (T20 series). Prior to data collection, the system and participant calibrations were performed. A total of 16 retro-reflective markers were attached to the participant's body following the lower body plug-in-gait model by an experienced investigator.

The subjects walked barefoot along an 8-meter walkway. They were asked to walk through the capture area at their own comfortable speed for 3 trials. All walking data were recorded with a frequency of $100 \mathrm{~Hz}$. A physical therapist walked beside the participants to prevent falling or any other hazardous situations. KT of $5 \mathrm{~cm}$ dimension was used in the study; it was applied with the inhibition technique on gastrocnemius muscle and with the functional correction technique for ankle dorsiflexion and eversion by a certified KT practitioner (Figure 1). The inhibition technique was used with the tension of $15-25 \%$ of the available tension of the tape and direction from the distal to proximal parts. The functional correction or spring assist technique was applied with the tension of $50-75 \%$ and direction from the distal to proximal parts [29]. After the taping was finished, the participants were asked about the feeling of taping to ensure proper application. As we wanted to exclude the factors of training or motor learning, as well as to allow KT to stimulate the sensory system, gait was captured 15 minutes after taping was finished. During this time, the subjects were asked to wait in a sitting position and listen to the details of gait assessment.

\section{Data processing and deduction}

Gait data were collected in the middle part of the walkway, and gait events were identified in accordance with the foot markers. Data were filtered with the $4^{\text {th }}$ order low pass Butterworth technique, with the cut-off frequency of $6 \mathrm{~Hz}$. The temporo-spatial and kinematic variables were processed by using the Nexus software. The averaged data from 3 walking trials be-

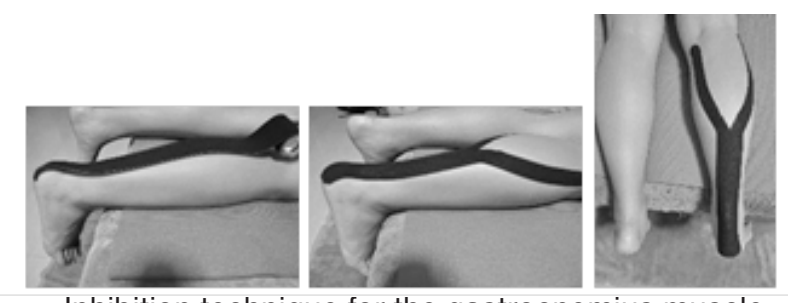

Inhibition technique for the gastrocnemius muscle
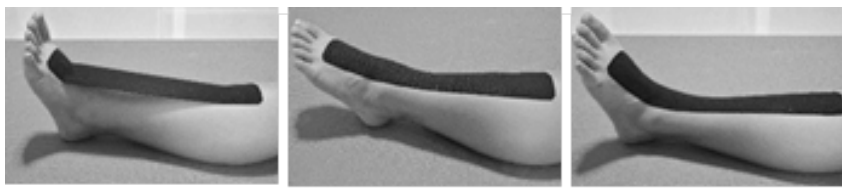

Functional correction for ankle dorsiflexion
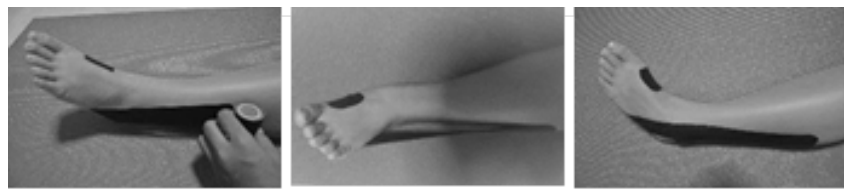

Functional correction for foot eversion

Figure 1. Kinesio Tape application

fore and immediately after KT application were used in the further analyses.

\section{Outcome variables}

Gait symmetry was determined as temporo-spatial and kinematic variables. The former included step length (m), step time (s), single support time (\% of gait cycle), the latter - peak hip flexion (degree), peak hip extension (degree), peak knee flexion (degree), $1^{\text {st }}$ peak ankle dorsiflexion (degree) at initial contact, $2^{\text {nd }}$ peak ankle dorsiflexion (degree) at the terminal stance, and peak ankle plantar flexion (degree) angles. Symmetry index (SI) (\%) was used to calculate gait symmetry with the following equation:

$$
\mathrm{SI}=\frac{\left(\mathrm{V}_{\text {affected }}-\mathrm{V}_{\text {unaffected }}\right)}{1 / 2\left({ }_{\text {Vaffected }}+\mathrm{V}_{\text {unaffected }}\right)} \times 100 \%
$$

where $\mathrm{V}$ represents the temporo-spatial or kinematic variables.

The SI value of $0 \%$ indicates perfect symmetry, while SI $\geq 100 \%$ implies asymmetry [30].

\section{Data analysis}

The data were computed by using the SPSS program with the statistical significance level set at $p<$ 0.05. The Kolmogorov-Smirnov goodness of fit test served to assess the distribution of the data. Because the data showed non-normal distribution, non-parametric statistics was applied. For descriptive data, medians and interquartile ranges were presented. 
A. Horasart, W. Klomjai, S. Bovonsunthonchai, Effect of Kinesio Tape on gait symmetry in stroke

The Wilcoxon signed rank test allowed to compare the data obtained before and immediately after KT application, as well as data for the affected and unaffected sides before and immediately after KT application.

In addition, correlations of the FMA-LE with the SI of the temporo-spatial (single support time, step time, and step length) and the kinematic (hip flexion, hip extension, knee flexion, $1^{\text {st }}$ peak ankle dorsiflexion, $2^{\text {nd }}$ peak ankle dorsiflexion, and ankle plantar flexion) variables before and after taping were analysed by using the Spearman correlation statistics. As SI data may present with positive or negative values depending on the side (affected or unaffected showed greater value), the absolute values of SI were used in this analysis to avoid misinterpretation of the binary correlation direction.

\section{Ethical approval}

The research related to human use has complied with all the relevant national regulations and institutional policies, has followed the tenets of the Declaration of Helsinki, and has been approved by the authors' institutional ethical committee (MU-CIRB 2017/010. 1701).

\section{Informed consent}

Informed consent has been obtained from all individuals included in this study.

\section{Results}

\section{Characteristics of the participants}

Demographic data are presented in Table 1. Ten patients with stroke ( 7 males and 3 females) participated in the study. Of this number, 9 subjects were ischemic and had the left side affected and 1 was haemorrhagic and had the right side affected. The average age, weight, height, and stroke onset time prior to the study were $58.60 \pm 14.37$ years, $59.79 \pm 10.69 \mathrm{~kg}, 165.25 \pm$ $6.76 \mathrm{~cm}$, and $9.80 \pm 5.37$ months, respectively. The average TMSE and FMA-LE scores equalled $29.10 \pm$ 1.10 and $28.50 \pm 4.08$. The MAS scores ranged $0-1$ for the hip adductor, hip extensor, knee extensor, and ankle invertor muscles, and 0-2 for the ankle plantar flexor. The exteroceptive sensations were tested on light touch, pain, and proprioception. Only 1 individual had impaired light touch and pain in the foot area; the remaining subjects had intact sensation.
Table 1. Demographic characteristic of participants

\begin{tabular}{lc}
\hline Variables & $\begin{array}{c}\text { Values (number or } \\
\text { mean } \pm S D \text { or range) }\end{array}$ \\
\hline Male/female $(n)$ & $7 / 3$ \\
Type (ischemic/haemorrhagic) & $9 / 1$ \\
Affected side (left/right) ( $n)$ & $9 / 1$ \\
Age (years) & $58.60 \pm 14.37$ \\
Weight (kg) & $59.79 \pm 10.69$ \\
Height (cm) & $165.25 \pm 6.76$ \\
Onset (months prior to the study) & $9.80 \pm 5.37$ \\
TMSE (score) & $29.10 \pm 1.10$ \\
FMA-LE (score) & $28.50 \pm 4.08$ \\
MAS for hip adductor (score) & $0-1$ \\
MAS for hip extensor (score) & $0-1$ \\
MAS for knee extensor (score) & $0-1$ \\
MAS for ankle plantar flexors & $0-2$ \\
(score) & $0-1$ \\
MAS for ankle invertor (score) & $1 / 9$ \\
Light touch (impaired/intact) $(n)$ & $1 / 9$ \\
Pain (impaired/intact) $(n)$ & $0 / 10$ \\
Proprioception (impaired/intact) $(n)$ &
\end{tabular}

$S D$ - standard deviation, TMSE - Thai Mental State Examination, FMA-LE - Fugl-Meyer assessment for lower extremity, MAS - Modified Ashworth Scale

Comparison of the temporo-spatial and kinematic variables between the affected and unaffected sides before and immediately after KT application

Table 2 presents the comparison of the temporospatial and kinematic variables between the affected and unaffected sides before and immediately after KT application. At baseline, significant differences of the single support time ( $p=0.005)$, step time ( $p=0.021)$, and angles of knee flexion $(p=0.015)$ and ankle plantar flexion ( $p=0.002)$ were found. The other temporo-spatial and kinematic variables did not differ. This reflected the asymmetrical gait pattern of patients with stroke in the temporal parameters as well as the angles of the knee and ankle. Immediately after KT application, significant differences of the single support time ( $p=0.005)$, step time ( $p=0.041)$, and angles of hip extension ( $p=0.037)$, knee flexion $(p=0.009)$, and ankle plantar flexion $(p=0.009)$ were observed.

Comparison of SI of temporo-spatial

and kinematic variables before

and immediately after KT application

Table 3 presents the comparison of SI of temporospatial and kinematic variables before and immediately after KT application. There were significant dif- 
Table 2. Comparison of temporo-spatial and kinematic data between affected and unaffected sides before and immediately after Kinesio Tape application

\begin{tabular}{|c|c|c|c|c|c|c|}
\hline \multirow[b]{2}{*}{ Variables } & \multicolumn{3}{|c|}{ Before Kinesio Tape application } & \multicolumn{3}{|c|}{ Immediately after Kinesio Tape application } \\
\hline & $\begin{array}{c}\text { Affected side } \\
\text { Median (Q1, Q3) }\end{array}$ & $\begin{array}{c}\text { Unaffected side } \\
\text { Median (Q1, Q3) }\end{array}$ & $p$-value* & $\begin{array}{c}\text { Affected side } \\
\text { Median (Q1, Q3) }\end{array}$ & $\begin{array}{c}\text { Unaffected side } \\
\text { Median (Q1, Q3) }\end{array}$ & $p$-value* \\
\hline \multicolumn{7}{|l|}{ Temporo-spatial } \\
\hline Single support time (\%GC) & $18.03(15.98,25.67)$ & $34.60(28.15,38.26)$ & $0.005 * *$ & $22.81(19.03,29.18)$ & $40.04(33.12,43.07)$ & $0.005^{* *}$ \\
\hline Step time (s) & $0.95(0.68,1.16)$ & $0.67(0.57,0.89)$ & $0.021 * *$ & $0.94(0.67,1.04)$ & $0.70(0.59,0.95)$ & $0.041 * *$ \\
\hline Step length $(\mathrm{m})$ & $0.29(0.18,0.40)$ & $0.27(0.14,0.40)$ & 0.541 & $0.40(0.25,0.46)$ & $0.36(0.20,0.45)$ & 0.308 \\
\hline Walking speed $(\mathrm{m} / \mathrm{s})$ & $0.31(0.24,0.43)$ & $0.28(0.25,0.48)$ & 0.306 & $0.38(0.30,0.57)$ & $0.40(0.30,0.56)$ & 0.865 \\
\hline Stride time (s) & $1.81(1.43,2.10)$ & $1.60(1.37,2.01)$ & 0.066 & $1.62(1.31,1.84)$ & $1.52(1.35,1.83)$ & 0.878 \\
\hline Stride length $(\mathrm{m})$ & $0.54(0.39,0.67)$ & $0.52(0.38,0.72)$ & 0.324 & $0.64(0.48,0.80)$ & $0.62(0.54,0.80)$ & 1.000 \\
\hline \multicolumn{7}{|l|}{ Kinematic (degree) } \\
\hline Hip flexion & $17.57(5.94,19.05)$ & $19.57(9.27,25.94)$ & 0.285 & $15.59(7.73,20.29)$ & $18.57(10.86,26.49)$ & 0.169 \\
\hline Hip extension & $9.12(5.22,17.89)$ & $15.40(6.69,21.45)$ & 0.203 & $9.09(5.52,16.51)$ & $17.11(9.15,22.20)$ & $0.037 * *$ \\
\hline Knee flexion & $16.44(10.37,30.18)$ & $47.20(36.26,51.52)$ & $0.015^{* *}$ & $19.82(15.46,32.45)$ & $47.43(42.23,51.50)$ & $0.009 * *$ \\
\hline $1^{\text {st }}$ peak ankle dorsiflexion & $6.96(4.37,11.10)$ & $6.26(4.15,8.98)$ & 0.646 & $8.20(4.53,12.26)$ & $6.61(3.92,9.33)$ & 0.114 \\
\hline $2^{\text {nd }}$ peak ankle dorsiflexion & $10.27(2.58,15.02)$ & $12.22(10.35,16.96)$ & 0.074 & $8.65(5.06,16.64)$ & $13.76(10.44,16.36)$ & 0.114 \\
\hline Ankle plantar flexion & $6.81(-1.20,9.99)$ & $11.03(7.86,17.27)$ & $0.022 * *$ & $6.71(-2.29,9.32)$ & $9.45(7.41,17.24)$ & $0.009 * *$ \\
\hline
\end{tabular}

GC - gait cycle

* significant difference tested by the Wilcoxon signed rank test at $p<0.05$

** significant difference

Table 3. Comparison of symmetry indices of temporo-spatial and kinematic variables before and immediately after Kinesio Tape application

\begin{tabular}{lccc}
\hline Variables & $\begin{array}{c}\text { Before } \\
\text { Kinesio Tape application } \\
\text { Median (Q1, Q3) }\end{array}$ & $\begin{array}{c}\text { Immediately after } \\
\text { Kinesio Tape application } \\
\text { Median }(\mathrm{Q} 1, \mathrm{Q})\end{array}$ \\
\hline Symmetry index of temporo-spatial variables $(\%)$ & & & \\
Single support time & $58.91(40.28,64.34)$ & $54.61(33.15,63.47)$ & 0.919 \\
Step time & $40.00(23.97,49.71)$ & $31.97(15.48,45.38)$ & $0.022^{* *}$ \\
Step length & $63.78(19.17,83.33)$ & $55.80(12.24,71.71)$ & $0.037 * *$ \\
\hline Symmetry index of kinematic variables $(\%)$ & & & 0.646 \\
Hip flexion & $35.87(12.70,89.58)$ & $40.28(14.21,83.44)$ & 0.878 \\
Hip extension & $37.12(11.93,105.90)$ & $24.17(12.43,88.83)$ \\
Knee flexion & $94.97(15.38,126.08)$ & $80.66(42.78,116.45)$ & 0.074 \\
$1^{\text {st }}$ peak ankle dorsiflexion & $61.24(17.18,147.28)$ & $69.50(12.11,121.97)$ & 0.878 \\
$2^{\text {nd }}$ peak ankle dorsiflexion & $47.23(6.68,125.97)$ & $60.68(12.93,79.49)$ & 0.799 \\
Ankle plantar flexion & $45.63(25.81,113.07)$ & $44.53(8.96,89.99)$ & 0.203 \\
\hline
\end{tabular}

\footnotetext{
* significant difference tested by the Wilcoxon signed rank test at $p<0.05$

** significant difference
}

ferences in the step time $(p=0.022)$ and step length $(p=0.037)$ before and immediately after KT application. The other temporo-spatial and kinematic variables did not differ.

Correlations of FMA-LE with SI

of temporo-spatial and kinematic variables

As shown in Figure 2, a significant correlation of FMA-LE and SI of step length was found, with mod- erate negative relationship immediately after KT taping $\left(r_{\mathrm{s}}=-0.69, p=0.026\right)$. The tendency of this relationship was observed but not significant before taping $\left(r_{\mathrm{s}}=\right.$ $-0.63, p=0.05)$. The other SIs of temporo-spatial and kinematic variables showed no correlations with FMA-LE $(p>0.05)$. 
A. Horasart, W. Klomjai, S. Bovonsunthonchai, Effect of Kinesio Tape on gait symmetry in stroke

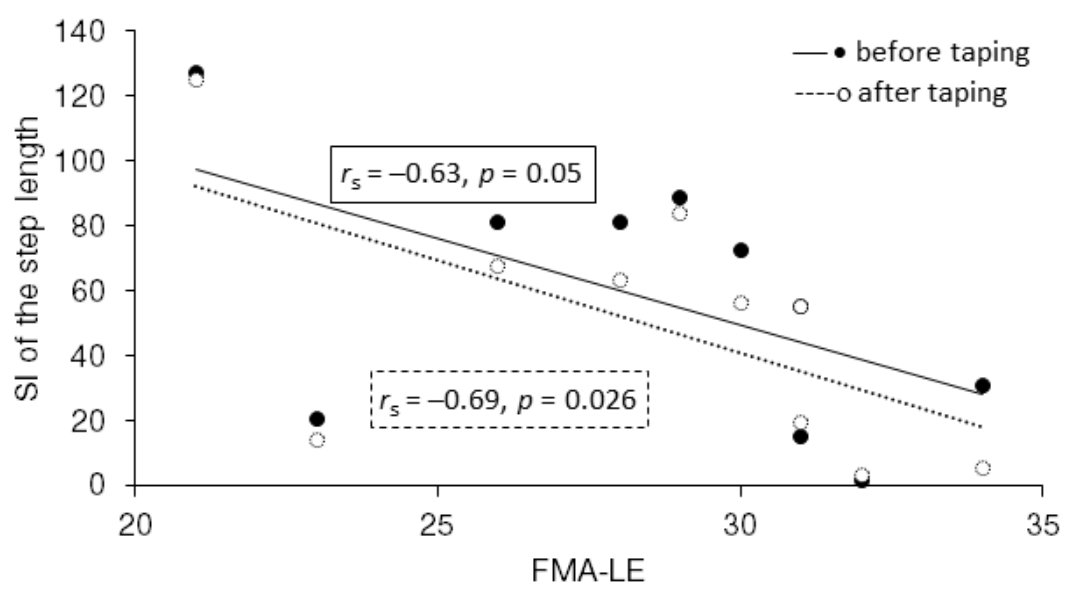

Figure 2. Correlation of the Fugl-Meyer assessment for lower extremity (FMA-LE) and the symmetry index (SI) of the step length

\section{Discussion}

Effect of Kinesio Tape on the temporo-spatial and kinematic variables and their symmetry indices

For the comparisons of temporo-spatial and kinematic data between affected and unaffected sides, there was no change in accordance with our expectation with the increased and decreased values for the unaffected and the affected sides, respectively. The values for the 2 sides should become similar to present a greater symmetry after the intervention. However, improvement was observed in some parameters, such as the increased single support time, step length, walking speed, stride length, and angles of knee flexion and $1^{\text {st }}$ peak ankle dorsiflexion of the affected leg.

After stroke, patients usually learn to use the remaining body parts to perform the functions and exhibit compensatory movements at the unaffected side. It may be difficult to restore normal gait patterns over a short period. The increased angles were found in the knee flexion and $1^{\text {st }}$ ankle dorsiflexion in this study. This may be due to the tape that we applied in the ankle and lower leg areas. As for the several mechanical stimuli to the visual, vestibular, and somatosensory systems, a previous study found that stimuli at the vestibular and/or the ankle proprioceptors showed greater contributions to leg muscle activities in persons with neuropathy than in those without neuropathy [31]. So, stimulating the sensation through the skin by taping may assist patients to better recognize and control the movement [17]. With the aims of reducing spasticity in the ankle plantar flexors and stimulating the dorsiflexors action, taping techniques used in this study were the inhibition technique for the ankle plan- tar flexor muscle and the functional correction technique for the ankle dorsiflexion and eversion.

It is well accepted that vision and vestibular sensation are the main factors that influence the control of movement and maintaining postural balance in both young adults and neurological patients [9, 32, 33]. However, by using the anticipatory and reactive controls, healthy young adults are able to adjust themselves to the external perturbation or certain sensory deprivation [32]. Good quality of movement requires the central nervous system and brain to select information from the several sensory inputs, anticipate, and generate proper muscular action to appropriately respond to the different types of tasks [34]. In post-stroke patients, the lesion occurring in the brain leads to the deprivation of motor control and perceptual functions. The reduction of these functions depends on the type, area, and size of the lesion. Most patients participating in this study were ischemic and had intact sensations. Taping with the aforementioned techniques aimed to relieve the spasticity of ankle plantar flexor muscles. With reference to the feasibility of KT on spasticity reduction, controversial findings were reported in previous studies. This may relate with the taping techniques used and the degree of spasticity. For our study, the degree of spasticity measured by MAS was set at $\leq 2$ in the inclusion criteria. This may enhance the ability to observe the effect of taping on gait performance. However, a recent review paper on 14 randomized control trials indicated that KT significantly improved lower extremity spasticity in patients with stroke [35]. The improvement of the $1^{\text {st }}$ ankle dorsiflexion angle in this study possibly came from the correction of the ankle dorsiflexor and evertor muscle. In addition, the improvement of knee flexion angle during the swing phase may have been influ- 
enced by a good adaptation over the early stance phase and the reduction of calf spasticity.

The improvement of SI of step time and step length after taping in the present study was consistent with a paper by Park and Lee [36]. They studied the immediate effect of KT application on left and right deviations during walking in patients with stroke. The results showed that KT could reduce walking deviation or increase gait symmetry. The enhancement of gait symmetry after KT application may be due to several factors. Firstly, KT stretched the skin continuously and mechanoreceptors were stimulated, which increased the amount of sensory information for the central nervous system. Hence, the ability to control movement was improved. Secondly, the techniques used in this study involved the correction for ankle eversion and dorsiflexion, which may have provided a cutaneous signal that corrected the ankle joint position and thus restored the joint range of motion and function. Finally, taping may help to support muscle function of tibialis anterior, resulting in a reduction of energy expenditure during the swing phase of gait. The findings were consistent with the participants' feeling, tested with an interview. The subjects reported less effort to dorsiflex the ankle during the swing phase. More explanations may be provided by a study by RojhaniShirazi et al. of 2015 [37]; they reported that KT application to the affected ankle dorsiflexors and evertors could correct equinovarus deformity and then improve postural balance variables. In addition, a recent study by Park performed in 2017 [38] found immediate improvement of cadence, speed, and affected stride length after applying a combination of proprioceptive neuromuscular facilitation (PNF) with elastic taping on quadriceps and tibialis anterior muscles in patients with stroke. However, there was no significant change of gait variables in either group that applied taping or PNF alone.

Even though no significant differences in SIs for other variables were shown, the symmetry of single support time, hip extension, knee flexion, and ankle plantar flexion tended to be improved after KT application. The SI values of some variables such as knee flexion, $1^{\text {st }}$ peak ankle dorsiflexion, $2^{\text {nd }}$ peak ankle dorsiflexion, and ankle plantar flexion presented values out of a \pm 100 range in this study. This may be caused by the fact that some patients demonstrated non-normal range of motion in a specific joint. So, the translation of the findings should be careful [39]. In previous studies, an improvement was observed of joint range of motion after KT combined with exercises implemented for at least 4 weeks $[13,17,40]$. Thus, appli- cation duration and combination with different types of exercise should be concerned in future studies to enhance and maintain gait performance in patients with stroke.

Correlations between lower extremity motor function and SIs of temporo-spatial and kinematic variables

Our second objective was to investigate the correlation of left extremity motor function and SIs of temporo-spatial and kinematic variables. We found a significant correlation of FMA-LE with the SI of step length only, whereas the other variables showed no correlation. Moderate correlation was observed immediately after KT taping $\left(r_{\mathrm{s}}=-0.69, p=0.026\right)$. This implies that the better the lower extremity motor function, the better step length symmetry was presented in patients with stroke. Given the items that constitute elements in the Fugl-Meyer assessment, we can presume that motor deficits of the affected side drive the changes of gait bilaterally. Similar findings were reported by Chow and Stokic in 2019 [28]: there were significant correlations of FMA-LE and SI of step length $(r=-0.40, p=0.009)$. This study also revealed correlations of FMA-LE and SI of stance time $(r=0.56, p<0.001)$, single support time $(r=0.64, p<0.001)$, and step cadence $(r=0.45$, $p<0.001$ ); however, we did not find any correlations among the remaining variables.

\section{Study limitations}

The limitations of the study included, firstly, a small number of participants. Secondly, a long-term followup for the effect of implementing KT is needed. Finally, a randomized controlled trial should be used to determine the effects of the intervention. Besides, the interpretation of the results and generalizability may be considered in the context of the population characteristics, such as the wide ranges of age and onset.

\section{Conclusions}

The benefits of KT application with the functional correction technique for ankle dorsiflexion and eversion and with the inhibition technique for gastrocnemius muscle were found for improving step length and step time symmetry. Therapists may apply KT as the alternative intervention technique to enhance gait performance in patients with stroke. The study may be limited by lack of a control group and by the small 
A. Horasart, W. Klomjai, S. Bovonsunthonchai, Effect of Kinesio Tape on gait symmetry in stroke

sample. In addition, a long-term study of effects of KT application as well as research in other techniques of taping should be conducted.

\section{Acknowledgements}

The study was supported by the National Research Council of Thailand grant, 2018 and Mahidol University. The authors would like to thank all the patients for participating in the study. Moreover, we are grateful to the staff from the Physical Therapy Center, Faculty of Physical Therapy, Mahidol University for their kind assistance throughout the study.

\section{Disclosure statement}

No author has any financial interest or received any financial benefit from this research.

\section{Conflict of interest}

The authors state no conflict of interest.

\section{References}

1. Sacco RL, Kasner SE, Broderick JP, Caplan LR, Connors JJ, Culebras A, et al. An updated definition of stroke for the 21st century: a statement for healthcare professionals from the American Heart Association/ American Stroke Association. Stroke. 2013;44(7): 2064-2089; doi: 10.1161/STR.0b013e318296aeca.

2. Suwanwela NC. Stroke epidemiology in Thailand. J Stroke. 2014;16(1):1-7; doi: 10.5853/jos.2014.16.1.1.

3. Krishnamurthi RV, Feigin VL, Forouzanfar MH, Mensah GA, Connor M, Bennett DA, et al. Global and regional burden of first-ever ischaemic and haemorrhagic stroke during 1990-2010: findings from the Global Burden of Disease Study 2010. Lancet Glob Health. 2013;1(5):e259-e281; doi: 10.1016/S2214109X(13)70089-5.

4. Brandstater ME, Basmajian JV. Stroke rehabilitation. Baltimore: Williams \& Wilkins; 1987.

5. Duncan PW, Zorowitz R, Bates B, Choi JY, Glasberg JJ, Graham GD, et al. Management of adult stroke rehabilitation care: a clinical practice guideline. Stroke. 2005;36(9):e100-e143;doi:10.1161/01.STR.0000180861. 54180.FF.

6. Yarkony GM, Sahgal V. Contractures. A major complication of craniocerebral trauma. Clin Orthop Relat Res. 1987;219:93-96.

7. Qiu F, Cole MH, Davids KW, Hennig EM, Silburn PA, Netscher H, et al. Effects of textured insoles on balance in people with Parkinson's disease. PLoS One. 2013;8(12):e83309; doi: 10.1371/journal.pone.0083309.

8. Mehrholz J, Pohl M, Kugler J, Elsner B. The improvement of walking ability following stroke. Dtsch Arztebl Int. 2018;115(39):639-645; doi: 10.3238/arztebl.2018. 0639 .
9. Tsaklis P, Zorzos SA, Mertyri D. Gait adaptations after vestibular stimulation in children with congenital visual impairments: a comparative study. Hum Mov. 2017;18(4):3-9; doi: 10.1515/humo-2017-0034.

10. Wei T-S, Liu P-T, Chang L-W, Liu S-Y. Gait asymmetry, ankle spasticity, and depression as independent predictors of falls in ambulatory stroke patients. PLoS One. 2017;12(5):e0177136; doi: 10.1371/journal.pone. 0177136.

11. Perry J, Burnfield JM. Gait analysis: normal and pathological function, $2^{\text {nd }}$ ed. Thorofare: Slack Incorporated; 2010.

12. Kluding PM, Dunning K, O’Dell MW, Wu SS, Ginosian J, Feld J, et al. Foot drop stimulation versus ankle foot orthosis after stroke: 30-week outcomes. Stroke. 2013;44(6):1660-1669; doi: 10.1161/STROKEAHA.111. 000334.

13. Lazarus C. The use of Kinesio ${ }^{\circledR}$ tape for the treatment of foot drop in a patient with sub-acute stroke: a case report. Fort Myers: Florida Gulf Coast University; 2013.

14. Lindquist AR, Prado CL, Barros RM, Mattioli R, da Costa PH, Salvini TF. Gait training combining partial body-weight support, a treadmill, and functional electrical stimulation: effects on poststroke gait. Phys Ther. 2007;87(9):1144-1154; doi: 10.2522/ptj.20050384.

15. Kase K, Tatsuyuki H, Tomoki O. Development of kinesio $^{\mathrm{TM}}$ tape. Kinesio ${ }^{\mathrm{TM}}$ taping perfect manual. Kinesio Taping Association; 1996.

16. Morris D, Jones D, Ryan H, Ryan CG. The clinical effects of Kinesio ${ }^{\circledR}$ Tex taping: a systematic review. Physiother Theory Pract. 2013;29(4):259-270; doi: 10.3109/ 09593985.2012.731675.

17. Choi Y-K, Nam C-W, Lee J-H, Park Y-H. The effects of taping prior to PNF treatment on lower extremity proprioception of hemiplegic patients. J Phys Ther Sci. 2013;25(9):1119-1122; doi: 10.1589/jpts.25.1119.

18. Guner S, Alsancak S, Koz M. Effect of two different Kinesio taping techniques on knee kinematics and kinetics in young females. J Phys Ther Sci. 2015;27(10): 3093-3096; doi: 10.1589/jpts.27.3093.

19. Kim YR, Kim JI, Kim YY, Kang KY, Kim BK, Park JH, et al. Effects of ankle joint taping on postural balance control in stroke patients. J Int Acad Phys Ther Res. 2012;3(2):413-478; doi: 10.5854/JIAPTR.2012.10.30. 446.

20. Kim W-I, Choi Y-K, Lee J-H, Park Y-H. The effect of muscle facilitation using Kinesio taping on walking and balance of stroke patients. J Phys Ther Sci. 2014; 26(11):1831-1834; doi: 10.1589/jpts.26.1831.

21. Fugl-Meyer AR, Jääskö L, Leyman I, Olsson S, Steglind S. The post-stroke hemiplegic patient. 1. A method for evaluation of physical performance. Scand J Rehabil Med. 1975;7(1):13-31.

22. Tamburini P, Mazzoli D, Stagni R. Towards an objective assessment of motor function in sub-acute stroke patients: relationship between clinical rating scales and instrumental gait stability indexes. Gait Posture. 2018;59:58-64; doi: 10.1016/j.gaitpost.2017.09.033. 
23. Mentiplay BF, Tan D, Williams G, Adair B, Pua YH, Bower KJ, et al. Assessment of isometric muscle strength and rate of torque development with hand-held dynamometry: test-retest reliability and relationship with gait velocity after stroke. J Biomech. 2018;75:171-175; doi: 10.1016/j.jbiomech.2018.04.032.

24. Wagenaar RC, Beek WJ. Hemiplegic gait: a kinematic analysis using walking speed as a basis. J Biomech. 1992;25(9):1007-1015; doi: 10.1016/0021-9290(92) 90036-z.

25. Awad LN, Reisman DS, Wright TR, Roos MA, BinderMacleod SA. Maximum walking speed is a key determinant of long distance walking function after stroke. Top Stroke Rehabil. 2014;21(6):502-509; doi: 10.1310/ tsr2106-502.

26. Zhang W, Smuck M, Legault C, Ith MA, Muaremi A, Aminian K. Gait symmetry assessment with a low back 3D accelerometer in post-stroke patients. Sensors. 2018;18(10):3322; doi: 10.3390/s18103322.

27. Guzik A, Drużbicki M, Przysada G, Kwolek A, Brzozowska-Magoń A, Sobolewski M. Relationships between walking velocity and distance and the symmetry of temporospatial parameters in chronic post-stroke subjects. Acta Bioeng Biomech. 2017;19(3):147-154; doi: 10.5277//ABB-00694-2016-02.

28. Chow JW, Stokic DS. Gait impairments in patients without lower limb hypertonia early poststroke are related to weakness of paretic knee flexors. Arch Phys Med Rehabil. 2019;100(6):1091-1101; doi: 10.1016/j. apmr.2018.10.014.

29. Kase K, Wallis J, Kase T. Clinical therapeutic applications of the Kinesio Taping method, $3^{\text {rd }}$ ed. Tokyo: Ken Ikai Co.; 2003.

30. Błażkiewicz M, Wiszomirska I, Wit A. Comparison of four methods of calculating the symmetry of spatialtemporal parameters of gait. Acta Bioeng Biomech. 2014; 16(1):29-35; doi: 10.5277/abb140104.

31. Wu G, Haugh L, Sarnow M, Hitt J. A neural network approach to motor-sensory relations during postural disturbance. Brain Res Bull. 2006;69(4):365-374; doi: 10.1016/j.brainresbull.2006.01.012.

32. Faquin BS, Candido CRC, Mochizuki L, Okazaki VHA. Effect of visual and vestibular information on spatial perception on gait. Hum Mov. 2018;19(2):3945; doi: 10.5114/hm.2018.74058.

33. Da Silva TC, Felippe LA, Carregaro RL, Christofoletti G. Postural instability in subjects with Parkinson's disease undergoing different sensory pitfalls. Hum Mov. 2017;18(4):55-60; doi: 10.1515/humo-2017-0031.

34. Proske U, Gandevia SC. The proprioceptive senses: their roles in signaling body shape, body position and movement, and muscle force. Physiol Rev. 2012;92(4): 1651-1697; doi: 10.1152/physrev.00048.2011.

35. Wang M, Pei ZW, Xiong BD, Meng XM, Chen XL, Liao WJ. Use of Kinesio taping in lower-extremity rehabilitation of post-stroke patients: a systematic review and meta-analysis. Complement Ther Clin Pract. 2019; 35:22-32; doi: 10.1016/j.ctcp.2019.01.008.
36. Park Y-H, Lee J-H. Effects of proprioceptive sensebased Kinesio taping on walking imbalance. J Phys Ther Sci. 2016;28(11):3060-3062; doi: 10.1589/jpts. 28.3060 .

37. Rojhani-Shirazi Z, Amirian S, Meftahi N. Effects of ankle Kinesio taping on postural control in stroke patients. J Stroke Cerebrovasc Dis. 2015;24(11):25652571; doi: 10.1016/j.jstrokecerebrovasdis.2015.07.008.

38. Park S-J. The immediate effects of proprioceptive neuromuscular facilitation with taping on gait parameters in patients with chronic stroke. J Phys Ther Sci. 2017;29(11):2018-2021; doi: 10.1589/jpts.29.2018.

39. Patterson KK, Gage WH, Brooks D, Black SE, McIlroy WE. Evaluation of gait symmetry after stroke: a comparison of current methods and recommendations for standardization. Gait Posture. 2010;31(2):241-246; doi: 10.1016/j.gaitpost.2009.10.014.

40. Lee JH. 2-dimensional analysis of low limb taping methods on ambulation for stroke patients. J Phys Ther Sci. 2017;29(6):1098-1101; doi: 10.1589/jpts.29.1098. 